\title{
Outcome of patients with arthritis and parvovirus B19 DNA in synovial membranes
}

\author{
Schmid, Simone ; Bossart, Walter ; Michel, Beat A ; Brühlmann, Pius
}

\begin{abstract}
To investigate the follow-up of the 17 patients during the period of 1995-2001 of the outpatient Clinic for Rheumatology at the University Hospital of Zurich with arthritis and the presence of parvovirus B19 DNA demonstrated by PCR in synovial biopsies. Seventeen patients of 163 with arthritis, which were routinely examined by needle arthroscopy during 1995-2001 with a positive parvovirus B19 DNA by PCR of synovial biopsy were reevaluated. Investigations included medical history, clinical examination and blood tests. Joint fluid was taken on patients with joint effusion. The observation period of the 17 patients $(\mathrm{F}: \mathrm{M}=11: 6)$ was 2 -8years $(\varnothing=6.5$ years $)$. In 8 of 17 patients the arthritis could not be classified neither at entry nor during the follow up of the study. The arthritis could be diagnosed in six patients early in the onset of the disease and included three cases of lyme arthritis of the knee joint, two cases with arthritis following a gastrointestinal infection (one with Salmonella typhimurium-positive faecal test - and the other one with a culture negative agent), one patient probably had an infection-associated arthritis after a gastrointestinal infection with Entamöeba histolytica (Schirmer et al. in Rheumatol Int 18:37-38, 1998; Kasliwal in Am J Proctol Gastroenterol Colon Rectal Surg 32:12, 16, 28, 1981; Haslock and Wright in J R Coll Phys Lond 8:1554-162, 1974; Than-Saw et al. in Trop Geogr Med 44:355$358,1992)$ with remission after antibiotic therapy. After a disease course of 9months one patient could be classified as rheumatoid arthritis in the presence of anti-cyclic citrullinated antibodies but lack of rheumatoid factor. One patient with polyarthritis developed psoriasis of the skin 22months later. From the nine patients with unclassified arthritis 4 (45\%) got into complete remission with no symptoms or signs of joint inflammation after a disease course of 9-45months, whereas $5(55 \%)$ still demonstrate active non erosive arthritis (disease duration between 3 and 10years). The presence of parvovirus B19 DNA in synovial tissue of patients with joint inflammation does not allow the diagnosis of parvovirus induced arthritis. If the arthritis remains unclassified and without erosions over time a virus associated aetiology may be assumed. However, no definitive diagnosis is possible even in the presence of parvovirus B19 DNA in synovial tissue
\end{abstract}

DOI: https://doi.org/10.1007/s00296-007-0337-2

Posted at the Zurich Open Repository and Archive, University of Zurich

ZORA URL: https://doi.org/10.5167/uzh-155729

Journal Article

Published Version

Originally published at:

Schmid, Simone; Bossart, Walter; Michel, Beat A; Brühlmann, Pius (2007). Outcome of patients with arthritis and parvovirus B19 DNA in synovial membranes. Rheumatology international, 27(8):747-751. DOI: https://doi.org/10.1007/s00296-007-0337-2 


\title{
Outcome of patients with arthritis and parvovirus B19 DNA in synovial membranes
}

\author{
Simone Schmid • Walter Bossart • Beat A. Michel • \\ Pius Brühlmann
}

Received: 14 October 2006 / Accepted: 24 February 2007 / Published online: 31 March 2007

(C) Springer-Verlag 2007

\begin{abstract}
To investigate the follow-up of the 17 patients during the period of 1995-2001 of the outpatient Clinic for Rheumatology at the University Hospital of Zurich with arthritis and the presence of parvovirus B19 DNA demonstrated by PCR in synovial biopsies. Seventeen patients of 163 with arthritis, which were routinely examined by needle arthroscopy during 1995-2001 with a positive parvovirus B19 DNA by PCR of synovial biopsy were reevaluated. Investigations included medical history, clinical examination and blood tests. Joint fluid was taken on patients with joint effusion. The observation period of the 17 patients ( $\mathrm{F}: \mathrm{M}=11: 6)$ was $2-8$ years $(\varnothing=6.5$ years). In 8 of 17 patients the arthritis could not be classified neither at entry nor during the follow up of the study. The arthritis could be diagnosed in six patients early in the onset of the disease and included three cases of lyme arthritis of the knee joint, two cases with arthritis following a gastrointestinal infection (one with Salmonella typhimurium-positive faecal test - and the other one with a culture negative agent), one patient probably had an infection-associated arthritis after a gastrointestinal infection with Entamöeba histolytica (Schirmer et al. in Rheumatol Int 18:37-38, 1998; Kasliwal in Am J Proctol Gastroenterol Colon Rectal Surg 32:12, 16, 28, 1981; Haslock and Wright in J R Coll Phys Lond 8:1554-162, 1974; Than-Saw et al. in Trop Geogr Med
\end{abstract}

\footnotetext{
S. Schmid · B. A. Michel · P. Brühlmann $(\varangle)$

Department of Rheumatology and Physical Medicine, University Hospital of Zurich, Gloria-strasse 25, 8091 Zurich, Switzerland

e-mail: pius.bruehlmann@usz.ch

W. Bossart

Department of Microbiology,

University of Zurich, 8091 Zurich, Switzerland
}

44:355-358, 1992) with remission after antibiotic therapy. After a disease course of 9 months one patient could be classified as rheumatoid arthritis in the presence of anticyclic citrullinated antibodies but lack of rheumatoid factor. One patient with polyarthritis developed psoriasis of the skin 22 months later. From the nine patients with unclassified arthritis 4 (45\%) got into complete remission with no symptoms or signs of joint inflammation after a disease course of 9-45 months, whereas 5 (55\%) still demonstrate active non erosive arthritis (disease duration between 3 and 10 years). The presence of parvovirus B19 DNA in synovial tissue of patients with joint inflammation does not allow the diagnosis of parvovirus induced arthritis. If the arthritis remains unclassified and without erosions over time a virus associated aetiology may be assumed. However, no definitive diagnosis is possible even in the presence of parvovirus B19 DNA in synovial tissue.

Keywords Parvovirus B19 - Arthritis · Needlearthroscopy $\cdot$ Synovial membrane

\section{Introduction}

Parvovirus B19 was discovered in 1975 in the blood of a healthy blood donor. It is a one-strand 5,600 base-long DNA virus, classified as an erythrovirus from the family of parvoviridae.

With a diameter of $2-26 \mathrm{~nm}$ it is one of the smallest viruses. The virus capsid is not surrounded by an outside membrane. It is extremely stable and infects preferably the precursor cells of the erythrocytes. Propagation occurs through droplets. It is mainly known as the cause of erythema infectiosum in children, causing mild fever and skin rash. A parvovirus B19 infection seldom occurs in adults, 
seropositivity was found in about $50 \%$ of young adults (1020 years) and even up to $80 \%$ in the age of $70-80$ years. The disease appears in normal individuals with exanthema, transient thrombo- and granulocytopenia as well as arthritis or arthralgias, less often includes persistent cytopenia, hepatitis or myocarditis [1-4].

In individuals with any disorder of the immune system the infection can lead to a chronic persistent anaemia, aplastic crises do also occur. An infection during pregnancy often results in hydrops faetalis, intrauterine death or miscarriage, regardless of whether the mother develops clinical symptoms or not $[5,6]$.

All joints may be affected in parvovirus B19-induced arthritis, although it most commonly involves the small joints of the hand (namely PIP and MCP) and feet, knee, ankle and wrist joints. The joint pattern is usually symmetrical, polyarticular and often self-limiting after several weeks or months $[7,8]$. There is no single test available to reliably link an arthritis to a parvovirus B19 infection. The diagnostic evaluation is based on clinical signs, serology (IgM and IgG), PCR tests of serum, joint samples and bone marrow. The significance of detectable B19 DNA by PCR in joint fluid and synovial membrane remains unclear.

The parvovirus B19 DNA genome has been found in healthy individuals with joint trauma as well as in patients with juvenile chronic arthritis [7]. The same is true for patients with rheumatoid arthritis and osteoarthritis $[9,10]$. The possibility of selective antibody failure to produce neutralising antibodies was evoked to explain the persistence of chronic arthritis [11].

The objective of this study was to examine the follow-up of patients with the presence of parvovirus B19 DNA in the synovial membrane. Of particular interest were the duration of the arthritis, the occurrence of erosions and the question whether the arthritis could be classified over time.

\section{Patients and methods}

We examined 17 patients, 11 women and 6 men, aged between 25 and 59 (average 41), who presented during 1995-2001 with arthritis of unknown origin. All were found to have a positive presenting a positive parvovirus B19 PCR as evaluated by synovial membrane biopsy taken by needle-arthroscopy. Fifteen patients could be re-examined; one patient moved away and one reported suffering from chronic reactive arthritis due to an urogenital infection with Chlamydia trachomatis. The patients were interviewed about their medical history, underwent clinical examination and a blood sample was carried out for serology and PCR at baseline.

Five of $17(35 \%)$ showed a joint effusion and aspiration was carried out. A second synovial biopsy was taken in one patient undergoing arthroscopic synovectomy. No other biopsies were carried out due to ethical reasons and lack of therapeutic consequences as well.

The following laboratory tests were performed: ESR, CRP, rheumatoid factor and the anti-CCP (anti-cyclic citrullinated peptid), IgG- and IgM-antibodies against parvovirus B19 and PCR of B19 DNA. The joint fluid was also tested for virus-DNA by PCR.

The presence of parvovirus B19 DNA was assessed by PCR as described by Cassinotti et al. [12] for acute phase specimen and by Aberham et al. [13] for reconvalesent phase specimen. The latter procedure is validated according to the current guidelines of the International Conference on Harmonization [14] and the Council of Europe [15]. Parvovirus B19 specific antibodies were detected by Elisa (Denka Seiken, Tokyo, Japan).

\section{Results}

The DNA tested by PCR was negative in all 17-blood samples. The Anti-B19-IgM indicating an acute infection was negative in all cases at the first and follow up visit as well. The Anti-B19-IgG, however, proving a previous virus contact, were positive in all cases at baseline. The CRP was elevated in four patients (one RA, one Psoriatic arthritis, one chronic unclassified arthritis and one patient with Lyme arthritis treated 8 years ago). No virus genome was found in the five joint fluids. Parvovirus B19 DNA was again detected by PCR 6 years after the first positive result in the synovial biopsy of one patient (only this patient was examined on the occasion of a surgical synovectomy) (Tables 1,2).

The five patients with unclassified arthritis still showed joint inflammation during follow up demonstrating the same pattern as found at baseline. Four of these showed a symmetric polyarthritis and one a monarthritis of the knee. Of $17(100 \%)$ cases of arthritis with positive parvovirus B19 DNA in the synovial tissues, 9 cases (53\%) remained unclear. Four of these nine cases $(23.5 \%)$ underwent complete remission with an average 15 months and five cases (29.4\%) had persistent arthritis over a mean of 6.5 years.

Eight patients $(47 \%)$ could be classified as follows: in three patients $(17,6 \%)$ a reactive arthritis following a gastrointestinal infection was diagnosed. In one of these cases Salmonella typhimurium (positive faecal test) and in another case no pathogen was detected. An infectionrelated arthritis after an infection with $E$. histolytica was assumed in one patient (positive faecal test) [2-4, 16]. All of them showed complete remission within 6 months (average disease duration 4.3 months). Lyme arthritis with positive serology and DNA PCR of Borrelia burgdorferi was found in three cases $(17.6 \%)$. All three cases recovered after antibiotic therapy within 3-8 months. One patient 
Table 1 Clinical data, Parvovirus B 19 infection markers in sera, synovial samples and bone marrow at study entry (1995-2001)

\begin{tabular}{|c|c|c|c|c|c|c|c|c|c|c|}
\hline $\begin{array}{l}\text { Patient } \\
\text { number }\end{array}$ & Sex & Age & Arthritis & $\begin{array}{l}\text { Serum IgG } \\
\text { Anti-B19 }\end{array}$ & $\begin{array}{l}\text { Serum IgM } \\
\text { Anti-B19 }\end{array}$ & $\begin{array}{l}\text { Blood } \\
\text { B19 DNA }\end{array}$ & $\begin{array}{l}\text { CRP } \\
(n<5 \mathrm{mg} / \mathrm{l})\end{array}$ & $\begin{array}{l}\text { Synovial fluid } \\
\text { B19 DNA }\end{array}$ & $\begin{array}{l}\text { Synovial biopsy } \\
\text { B19 DNA }\end{array}$ & $\begin{array}{l}\text { Bone marrow } \\
\text { B19 DNA }\end{array}$ \\
\hline 1 & M & 29 & Poly & Pos & $\mathrm{Neg}$ & Pos & 69 & Neg & Pos & Neg \\
\hline 2 & $\mathrm{~F}$ & 44 & Mono (knee) & Pos & $\mathrm{Neg}$ & Neg & Normal & $\mathrm{Neg}$ & Pos & $\mathrm{Neg}$ \\
\hline 3 & $\mathrm{~F}$ & 33 & Poly & Pos & Neg & Neg & Normal & Neg & Pos & Pos \\
\hline 4 & $\mathrm{~F}$ & 37 & Mono (knee) & Pos & Neg & Neg & Normal & $\mathrm{Neg}$ & Pos & Neg \\
\hline 5 & M & 31 & Mono (knee) & Pos & Neg & $\mathrm{Neg}$ & 61 & Neg & Pos & Neg \\
\hline 6 & $\mathrm{~F}$ & 43 & Poly & Pos & Neg & Neg & 55 & Neg & Pos & - \\
\hline 7 & $\mathrm{~F}$ & 48 & Mono (knee) & Pos & Neg & $\mathrm{Neg}$ & 18 & $\mathrm{Neg}$ & Pos & Pos \\
\hline 8 & M & 28 & Oligo & Pos & Neg & Neg & 63 & Neg & Pos & Neg \\
\hline 9 & M & 37 & Oligo & Pos & $\mathrm{Neg}$ & $\mathrm{Neg}$ & Normal & $\mathrm{Neg}$ & Pos & $\mathrm{Neg}$ \\
\hline 10 & $\mathrm{~F}$ & 29 & Poly & Pos & $\mathrm{Neg}$ & $\mathrm{Neg}$ & 14 & $\mathrm{Neg}$ & Pos & - \\
\hline 11 & $\mathrm{~F}$ & 19 & Poly & Pos & $\mathrm{Neg}$ & $\mathrm{Neg}$ & Normal & $\mathrm{Neg}$ & Pos & - \\
\hline 12 & $\mathrm{~F}$ & 53 & Poly & Pos & $\mathrm{Neg}$ & $\mathrm{Neg}$ & Normal & $\mathrm{Neg}$ & Pos & Pos \\
\hline 13 & M & 33 & Mono & Pos & $\mathrm{Neg}$ & Neg & 38 & $\mathrm{Neg}$ & Pos & Pos \\
\hline 14 & $\mathrm{~F}$ & 23 & Oligo & Pos & Neg & Neg & 25 & Neg & Pos & Pos \\
\hline 15 & $\mathrm{~F}$ & 28 & Poly & Pos & $\mathrm{Neg}$ & Neg & Normal & $\mathrm{Neg}$ & Pos & Pos \\
\hline 16 & M & 44 & Poly & Pos & $\mathrm{Neg}$ & Neg & 39 & Neg & Pos & Pos \\
\hline 17 & $\mathrm{~F}$ & 41 & Mono (knee) & Pos & $\mathrm{Neg}$ & Pos & Normal & Pos & Pos & Pos \\
\hline
\end{tabular}

(5.9\%) was diagnosed as psoriatic arthritis when characteristic skin manifestations appeared 3 months after disease onset. One patient $(5.9 \%)$ developed erosive rheumatoid arthritis with a positive anti-CCP titer but negative rheumatoid factor.

\section{Discussion}

The diagnosis of parvovirus arthritis is easily missed because the typical viral exanthema is best known to pediatricians, while the associated joint complaints occur primarily in adults, often without skin involvement [17]. Failure to obtain parvovirus B19 serology at the time of arthritis presentation may leave the early diagnostic IgM antibody response undetected. On the other hand, persistent joint activity in later stage disease is more difficult to classify [18]. While the seroprevalence of B19 IgG in the adult population is $40-60 \%$, such positive $\operatorname{IgG}$ titers are non-specific and do not necessarily imply a recent infection [19]. PCR has been used diagnostically for detection of B19 DNA in many different clinical specimens $[12,20]$. The value of the presence of B19 DNA in the synovial membrane for the diagnosis of B19 associated arthritis is controversial. There are reports of detectable B19 DNA in joint samples of patients with chronic juvenile arthritis, in healthy individuals with joint damage due to trauma [7], in patients with rheumatoid arthritis and osteoarthritis $[9,10]$.

In this follow-up study of arthritis patients with a positive synovial biopsy for B19 DNA at entry nearly half of them could be classified as Lyme disease, reactive arthritis, psoriatic arthritis and rheumatoid arthritis. In these patients the detection of viral genome does probably not prove the viral aetiology of the joint inflammation.

In 53\% of patients the arthritis remained unclassified. Forty five percent of these arthritis healed spontaneously without signs of joint damage within several months or a few years respectively. B19 DNA in blood samples and synovial fluid was detected in one patient at the first examination and became negative in the follow-up. Either synovial biopsies nor bone marrow aspirations were taken in all these asymptomatic people therefore no information about the B19 genome status were available. Despite other clinical or laboratory findings these patients have been suggested to have a probable diagnosis of B19 associated arthritis.

The other 55\% showed a chronic persistence of synovial inflammation mostly over a couple of years without joint destruction or symptoms of other organ systems or of the skin. All patients except one (monarthritis of the knee joint) showed symmetric polyarthritis of small and large joints. Chronic B19 arthropathies over months to years are described [21, 22]. In these cases most commonly the small joint of the hands, feet, wrists, knees and ankles symmetrically were involved mimicking early RA. The development of erosions or nodules is rarely reported [23, 24]. Since human parvovirus B19 infection is common and the clinical picture of early RA and B19 arthritis may be undistinguishable some cases might be the result of a coincidence of the two diseases. No information about B19 DNA detected by 


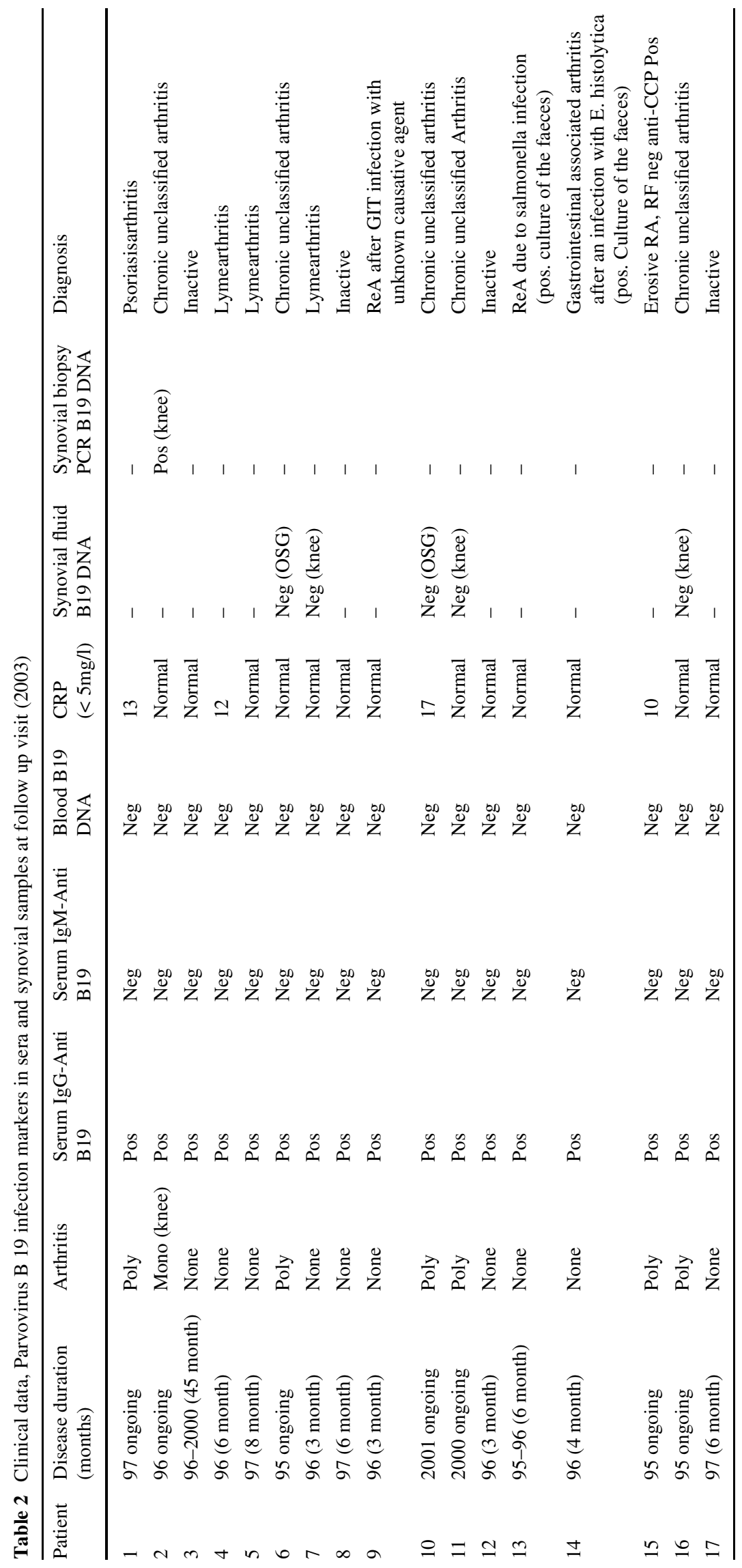


PCR in synovial samples or bone marrow were available in these reports. The significance of parvovirus B19 DNA in the synovium of established RA patients still remains controversial $[9,25,26]$. It was hypothesized that a proportion of patients with a diagnosis of seronegative RA and a few patients with rheumatoid factor positive RA that has a begin anerosive course, have chronic parvovirus B19 arthropathy [27]. A second synovial biopsy in one of our chronic patients revealed B19 DNA indicating persistence of either B19 virus or at least select B19 DNA sequences in the joint. In all other cases B 19 DNA could not be detected either in synovial fluid or in blood samples during follow-up.

The fact that during follow-up no samples of synovial tissue and bone marrow were taken represents a limitation our study. It would have been of interest to know whether DNA sequences of the virus can still be identified in the synovial membrane in the remaining cases of persisting arthritis. However, due to ethical reasons and lack of therapeutic consequences these tissue samples were not available any more. In summary, the value of parvovirus B19 genome detection in the synovial tissue in an occasional arthritis patient is still unclear. If the arthritis remains unclassified a positive result of B19 DNA of the synovium in patients with Anti-B19 IgG antibodies can indicate a virus-induced arthritis with a favourable outcome. Even in patients with persistent arthritis synovial B19 DNA along with a serological Anit-B19 IgG response may not be diagnostic.

\section{References}

1. Schirmer M, Fischer M, Rossboth DW, Mur E, Dierich MP, Frischhut B (1998) Entamoeba hartmanni: a new causative agent in the pathogenesis of reactive arthritis? Rheumatol Int 18:37-38

2. Kasliwal RM (1981) Chronic colitis and arthritis with special emphasis on amoebic colitis. Am J Proctol Gastroenterol Colon Rectal Surg 32:12, 16, 28

3. Haslock I, Wright V (1974) Arthritis and intestinal disease. J R Coll Phys Lond 8:154-162

4. Than-Saw, Mar-Mar-Nyein, Oo MM et al (1992) Isolation of Entamoeba histolytica from arthritic knee joint. Trop Geogr Med 44:355-358

5. Modrow S (2001) Parvovirus B19: Ein Infektionserreger mit vielen Erkrankungensbildern. Dtsch Arztebl 98:A1620-1624

6. Stoll T, Bruhlmann P, Brunner U, Treier A, Cassinotti P, Michel BA (1995) Parvovirus-B19-induced arthritis/arthropathy-an important differential diagnosis of chronic polyarthritis. Schweiz Med Wochenschr 125:347-354

7. Soderlund M, von Essen R, Haapasaari J, Kiistala U, Kiviluoto O, Hedman K (1997) Persistence of parvovirus B19 DNA in synovial membranes of young patients with and without chronic arthropathy. Lancet 349:1063-1065
8. Speyer I, Breedveld FC, Dijkmans BA (1998) Human parvovirus B19 infection is not followed by inflammatory joint disease during long term follow-up. A retrospective study of 54 patients Clin Exp Rheumatol 16:576-578

9. Saal JG, Steidle M, Einsele H, Muller CA, Fritz P, Zacher J (1992) Persistence of B19 parvovirus in synovial membranes of patients with rheumatoid arthritis. Rheumatol Int 12:147-151

10. Kerr LR, Cartron JP, Curran MD, Moore JE, Elliot JR, Mollan RA (1995) A study of the role of parvovirus B19 in rheumatoid arthritis. Br J Rheumatol 34:809-813

11. Foto F, Saag KG, Scharosch LL, Howard EJ, Naides SJ (1993) Parvovirus B19-specific DNA in bone marrow from B19 arthropathy patients: evidence for B19 virus persistence. J Infect Dis 167:744-748

12. Cassinotti P, Siegl G, Michel BA, Bruhlmann P (1998) Presence and significance of human parvovirus B19 DNA in synovial membranes and bone marrow from patients with arthritis of unknown origin. J Med Virol 56:199-204

13. Aberham C, Pendl C, Gross P, Zerlauth G, Gessner M (2001) A quantitative, internally controlled real-time PCR Assay for the detection of parvovirus B19 DNA. J Virol Methods 92:183-191

14. Smith PF (1996) Third international conference on harmonization of technical requirements for the registration of pharmaceuticals for human use-a toxicologist's perspective. Toxicol Pathol 24:519-528

15. Guidelines of the Council of Europe (1999) PA/PH/OMCL (98) 22, DEF

16. Kasliwal RM (1973) Clinical amoebiasis syndrome and case reports of a few unusual cases of amoebiasis. Am J Proctol 24:326332

17. Woolf AD, Campion GV, Chishick A et al (1989) Clinical manifestations of human parvovirus B19 in adults. Arch Intern Med 149:1153-1156

18. Naides SJ, Field EH (1988) Transient rheumatoid factor positivity in acute human parvovirus B19 infection. Arch Intern Med 148:2587-2589

19. Anderson LJ (1990) Human parvovirus B19. Pediatr Ann 19:509_ $10,512-513$

20. Clewley JP (1989) Polymerase chain reaction assay of parvovirus B19 DNA in clinical specimens. J Clin Microbiol 27:2647-2651

21. Kerr JR, Cunniffe VS (2000) Antibodies to parvovirus B19 nonstructural protein are associated with chronic but not acute arthritis following B19 infection. Rheumatology (Oxford) 39:903-908

22. Naides SJ (1998) Rheumatic manifestations of parvovirus B19 infection. Rheum Dis Clin North Am 24:375-401

23. Cohen BJ, Buckley MM, Clewley JP, Jones VE, Puttick AH, Jacoby RK (1986) Human parvovirus infection in early rheumatoid and inflammatory arthritis. Ann Rheum Dis 45:832-838

24. Tyndall A, Jelk W, Hirsch HH (1994) Parvovirus B19 and erosive polyarthritis. Lancet 343:480-481

25. Nikkari S, Roivainen A, Hannonen P et al (1995) Persistence of parvovirus B19 in synovial fluid and bone marrow. Ann Rheum Dis 54:597-600

26. Takahashi Y, Murai C, Shibata S et al (1998) Human parvovirus B19 as a causative agent for rheumatoid arthritis. Proc Natl Acad Sci USA 95:8227-8232

27. Naides SJ, Scharosch LL, Foto F, Howard EJ (1990) Rheumatologic manifestations of human parvovirus B19 infection in adults. Initial two-year clinical experience. Arthritis Rheum 33:12971309 